\title{
Ações coletivas e suas configurações antiutilitaristas: \\ O caso colombiano da Marcha Patriótica
}

\author{
BERMEO, Dana Milena Chávarro ${ }^{1}$ \\ PINHEIRO, Wellington $D^{2}{ }^{2}$
}

\section{RESUMO}

O artigo discute a configuração solidária de prática social encontrada no Movimento político e social Marcha Patriótica (MARCHA) ${ }^{3}$. Sendo a Marcha um dos movimentos que obteve maior protagonismo no processo de negociação entre o governo Santos e as guerrilhas das FARC-EP ela nos possibilitou identificar a construção do projeto político colombiano de reivindicar a paz como um bem comum daquela nação. Neste sentido, mobilizamos a teoria da dádiva a fim de compreender como os conceitos de gratuidade e de obrigação do agir encontrados nas ações estratégicas do movimento metamorfoseou a ideia da paz entendendo-a como um bem de justiça social. Para tal fim analisamos o fenómeno da Ruana com intuito de demonstrar como a gênese do movimento e o projeto de articulação política caracterizaram a dimensão antiutilitarista e solidária desta ação coletiva.

Ações coletivas. Anti-utilitarismo. Solidariedade moderna

\section{Collective actions and its anti-utilitarian configurations: The Colombian} case of Marcha Patriótica

The social base of the movement "Movimiento Social y Político Marcha Patriótica" (MARCHA) has a key role in the social practice. MARCHA has one of the most important roles in the Colombia peace process; this is between the Santos Government and the guerrilla (FARC-EP). This MARCHA movement allows to understand Peace, like a common wealth of the nation, in the current political project in Colombia. The way of recognize this common wealth is mainly with Dadiva theory. This theory appreciate how the combination of the two concepts, duty and free, transform the idea of Peace. The feature of the change is the Ruana (Typical Colombian cloth) symbol, that probes how the beginning of the movement and the political articulation summarize the antiutilitarian and social dimension of this collective action.

\section{Collective action. Anti-utilitarianism. Modern solidarity}

\footnotetext{
${ }^{1}$ Doutoranda em Sociologia, Universidade Federal de Pernambuco - UFPE, Bolsista do Programa Estudantes-Convênio de Pós-Graduação - PEC-PG, da CAPES/CNPq - Brasil. danachabe@yahoo.com

${ }^{2}$ Doutor em Educação-UFPE, professor da Faculdade Osman da Costa Lins (FACOL), pinheiraosociais@yahoo.com.br

${ }^{3}$ Esta discussão faz parte da nossa tese em andamento intitulada: Novas possibilidades de Interpretação das Mobilizações Sociais na América Latina: Comparando Brasil e Colômbia
} 


\section{INTRODUÇÃO}

Nestes últimos anos, o protagonismo dos movimentos sociais descortinou novos horizontes de sentido a fim tecer respostas à crise conjuntural política-formativa-social que atingiu a sociedade em escala mundial, sobretudo na América Latina.

No contexto das ações coletivas autores como Bringel \& Pleyers (2017) reiteram a severidade da crise e identificam a emergência de um novo contexto para o estudo das ações coletivas. Estes autores afirmam que estamos vivendo um novo ciclo de confronto social ora denominado ciclo de indignação.

Deste modo ao nos debruçarmos sobre o estudo das ações coletivas inspirado neste novo patamar de acontecimentos fomos imbuídos a (re)pensar outras possibilidades de compreender como os atores coletivos reinventaram suas práticas sociais. Mais ainda quando os movimentos emancipatórios têm que lidar com a onda conservadora populista que contagia parte das populações pobres. Porém, justamente por causa destes movimentos de direita estarem avançando é importante explicar a presença e a força de movimentos sociais mais à esquerda que continuam a sinalizar a democratização do processo colombiano.

Aprofundando a incursão na temática das ações coletivas compreendemos a complexidade das mobilizações sociais pós-segunda década do século XXI. Isto exigiu cada vez mais dos estudiosos o empenho de ferramentas teóricas que permitam rediscutir aproximações e acompanhar situações das ações coletivas numa época inédita do protagonismo social (GOHN,2017; BRINGEL \& PLEYERS, 2017).

Portanto, para a especificidade desta publicação, situamos nossa discussão sobre as ações coletivas do movimento político e social Marcha Patriótica (MARCHA) o que nos permitiu entender parte da conjuntura políticosocial colombiana, como também nos possibilitou identificar a construção do projeto político andino de reivindicar a construção da paz como um bem comum $^{4}$ daquela nação.

Por seu turno, o movimento MARCHA "nasceu" no dia 21 de abril de 2012 numa das maiores manifestações já registrada na Colômbia. Sua plataforma político-cultural acolhe camponeses, indígenas, coletivos de

\footnotetext{
${ }^{4} \mathrm{O}$ "bem comum" ou o chamado "procomún" (versão castelhana do termo anglo-saxão "commons") é uma modalidade de governabilidade para os bens coletivos. Tal termo aglutina aqueles bens, recursos, processos ou coisas (sejam elas materiais ou intangíveis) cujos benefícios, posses ou direitos de exploração pertencem a um grupo ou a uma comunidade determinada de pessoas (MARTINS \& ARAUJO, 2016, p. 14)

${ }^{5}$ Optamos pela nomeação do movimento como "Marcha" respeitando a maneira "familiar" como os militantes, que conhecemos no trabalho de campo, referem-se cotidianamente à organização. No entanto, é prudente reconhecer que nos documentos oficiais, nos comunicados e nas cartilhas educativo-informativas do movimento utilizam-se a sigla MAPA.
} 
mulheres, movimento estudantil e muitas outras organizações sociais representativas do território nacional.

Assim, nos documentos oficiais da Marcha sinalizam para o fato de que a confluência de indivíduos se constitui num processo que articulou atores coletivos e plurais advindos de diversas organizações. No contexto desta diversidade há que se perceber a relevância de alguns atores políticoinstitucionais que fazem parte do movimento. Sobretudo, destacamos a presença do Partido Comunista Colombiano (PCC), o Poder Ciudadano (PC), a Asociación Campesina del Valle del Rio Cimitarra (ACVC).

Ainda descrevendo a emergência do movimento é importante perceber que, segundo Lozano Guillén (2014), Marcha Patriótica surge antes dos processos de diálogos de paz em Havana (Cuba) 2012. Marcha, naquela época, realizou o esforço de organizar tantos setores rurais quanto os urbanosindicais e outros representantes de organizações populares.

Para este autor um dos principais antecedentes ocorreu no Encuentro Campesino, Afrodescendiente e Indígena del Magdalena Medio (2009). Tal evento foi promovido por diferentes coletivos preocupados em defender a temática da paz como um projeto político da nação. Dentre várias organizações sociais que formaram o encontro destacamos o protagonismo da Asociación Campesina del Valle del Rio Cimitarra (ACVC), a qual recebeu o prêmio nacional da paz $(2010)^{6}$.

Nesta linha de raciocínio observamos que a Asociación de Zona de Reserva Campesina (AZRC), a Federación de Estudiantes Universitários (FEU), o coletivo Maestros em Marcha, a Coordinadora Nacional Agraria Popular (CONAP), a Asociación Colombiana de Estudiantes Universitarios (ACEU), e a Mesa Amplia Nacional Estudiantil (MANE) também estão articulados à causa da paz mobilizada pela Marcha.

No tocante a organização político-estratégica do movimento nossa pesquisa de campo, sobretudo a entrevista em profundidade com um dos voceros $^{7}$ do movimento revelou que Marcha patriótica está conformada por três grandes setores: o primeiro o PCC, o segundo Poder Ciudadano, que pertence a esquerda Liberal e a CONAP criado 2007 e tem como caraterística principal a congregação dos setores rurais que fazem parte da Marcha (AMAUTA, 2017).

\footnotetext{
${ }^{6}$ A ACVC desenvolveu um processo de resistência camponesa no conflito mantido por muitos anos contra o paramilitarismo e a política da "seguridade democrática" dos governos Uribe Vélez (2002-2010) que tentou pôr fim às zonas de reserva camponesa. A ACVC obteve o Prêmio Nacional de Paz 2010. Para maiores esclarecimentos sobre este reconhecimento ler: La Asociación Campesina del Valle del Río Cimitarra - ACVC: Premio Nacional de Paz 2010. https://www.prensarural.org/spip/spip.php?article4898

${ }^{7} \mathrm{~A}$ tradução de vocero para o português poderia ser equivalente à Porta-voz, porém achamos interessante manter a palavra no espanhol, na medida em que com esta denominação se conhece a aqueles militantes da Marcha que advogam em nome do movimento e compartilham uma liderança com funções e atividades políticas concretas o que supera a concepção tradicional de porta-voz.
} 
Porém, didaticamente, podemos falar de três blocos: o primeiro é o bloco agrário constituído pelas organizações camponesas, organizações indígenas e organizações afrocolombianas. Há o segundo bloco formado pelo público juvenil-estudantil; por fim, o terceiro seguimento é constituído pelos coletivos de cidadania de bairros e das vítimas do conflito armado.

Para a especificidade deste artigo nos detemos sobre a questão da gênese do movimento, a discussão do projeto de articulação política e os repertórios de confronto. Por conseguinte, foi possível entender como o desenvolvimento solidário desta ação coletiva ressignificou a causa social da paz como um bem comum da nação.

Pois como será demonstrada a construção da solidariedade moderna termina sendo basilar numa "sociedade política ativa que se desdobra entre reações pela ampliação de direitos e aqueles outras voltadas para organização de sistemas comunitários autônomos" (MARTINS, 2019, p. 168).

Após esta apresentação da discussão, sinteticamente, 0 artigo foi organizado do seguinte modo. Na primeira parte tecemos nossa abordagem teórica e apresentamos o processo de paz como parte da contextualização política das ações coletivas do movimento. Na segunda lançamos um olhar interpretativo sobre o fenômeno do Paro Nacional Agrário ao identificarmos neste evento social processos solidários que mobilizaram força antiutilitarista 0 que ressignificou a performance do confronto político. Por fim, tecemos nossas considerações finais.

\section{Negociação no conflito armado e a construção da paz com justiça social}

Com o intuito de aproximar o debate desta ação coletiva com a discussão antiutilitarista que envolve o contexto de interterritórios políticoculturais das práticas sociais reivindicadas pela Marcha mobilizamos 0 paradigma da dádiva entendendo-o como um fato social capaz de interpretar de forma autêntica as interações desinteressadas e solidárias que vem sendo proposta por este movimento popular na Colômbia.

Segundo Martins (2005) O caráter antiutilitarista da teoria da dádiva pretende denotar "o equívoco de toda tentativa de limitar as motivações humanas apenas à moral do interesse e do egoísmo e de privilegiar a economia de mercado como instância privilegiada na produção do bem-estar social" (p. 53).

Assim, o entendimento da triple obrigação (dar-receber-retribuir) no sentido sociológico da dádiva vai ajudar na nossa discussão na medida em que, ela é o motivo basilar para a existência de alianças e vínculos sociais que geram vida em comunidade (CAILLÉ, 2002). 
Nesta perspectiva teórica ao entender a realidade como intrinsicamente simbólica (CAILLÉ, 2002) veremos como nas ações simbólico-solidárias da Marcha acionadas pela força do bem simbólico da Ruana, que expressa um tipo de dádiva, é capaz de promover rituais de confiança, amizade e solidariedade moderna.

A Ruana é uma palavra de origem chibcha que significa "terra de cobertores", é um tipo de vestuário de estilo poncho exterior típico da região dos andes da Colômbia. Ela in situ já é símbolo de austeridade, de força espartana, de trabalho, de lavoro e de muito empenho.

Em 2013 ela foi lembrada por um dos líderes da greve dos produtores de cebola "Esse dia a ruana deixou de ser um cobertor para transformar-se num símbolo de resistência e soube que isto devia crescer até transformar-se no que terminou sendo a greve nacional agraria daquele ano" (EL ESPECTADOR, 2013d). Desta maneira a ruana será expressão simbólica de certa gratuidade do agir como veremos na frente.

Não em tanto, antes de continuar avançando nesta perspectiva se faz necessário compreender alguns elementos estratégicos do agir da Marcha para finalmente demonstrar como a gênese do movimento e o projeto de articulação política caracterizaram a dimensão antiutilitarista e solidária desta ação coletiva.

O lema simbólico "pela segunda e definitiva independência" constituiu um fator de mobilização para MARCHA, na medida em que a construção de espaços de convivência democrática enfatizou uma mensagem clara e contundente sobre a necessidade de transformar a luta participativa em prol da cultura de paz.

Tal lema enfocou uma visão ativista que reivindicava a emergência de um bem coletivo, um propósito político que questionasse o sistema económico neo-extrativista e o sistema democrático representativo economicista (MARCHA PATRIÓTICA, S/D).

Com efeito, este sentimento de luta social é expresso pela militante Ângela Maria Robledo ao enfatizar sua adesão à Marcha Patriótica:

No dia 21 de abril estive ali. Aquilo foi um grande cenário democrático [...] adicionei-me à proposta da Marcha Patriótica de assinar e ressaltar que na Colômbia a paz é urgente e possível. E para que a paz seja verdadeira e durável é necessário que o barulho dos fuzis e das bombas silencie, mas também como o Mestre Fals Borda diz que se enraíze no ethos de resistência (ROBLEDO, 2014, tradução nossa).

Esta passagem constitui uma primeira possibilidade de entender as ações coletivas da Marcha Patriótica na qual a ideia de interesse ou 
desinteresse mobilizada em suas lutas reivindica a constituição de uma cosmovisão antiutilitarista. Tal abordagem defende uma cultura de paz amparada por princípios morais que são traduzidos pelas práticas de bons costumes, da confiança, da construção de normas de convivência e da socialização de ideias não mercantis guiada pelo espírito democrático-moral da paz como um bem social da nação.

Deste modo é valioso perceber que a postura político-social da Marcha nunca esteve alheia ao processo de paz. Suas ações ficaram registradas historicamente na comemoração do bicentenário da independência. Neste evento realizou-se a primeira grande ação coletiva: "Marcha Patriótica y Cabildo Abierto por la Independência".

Sobre isso é importante reconhecer que:

A procura da paz na Colômbia pelo caminho pacífico de entendimento e acordos sem bases militares no nosso espaço nacional e com total autodeterminação seria uma grande conquista na luta dos povos. Neste empenho convocamos a população através da Marcha Patriótica pela independência pela soberania, pela paz e pelos direitos populares (MARCHA PATRIÓTICA, 2010, tradução nossa).

Esta passagem nos permite compreender que a luta pela paz é vista como uma aposta na transformação estrutural da Colômbia. Simbolicamente as mobilizações em defesa da paz configuram-se num convite para aprofundar a democracia, a justiça social e a soberania da nação que devido ao histórico combate à violência teve e ainda tem seu território governamentalizado por várias bases militares do imperialismo norte-americano.

Para além desses fatos tais manifestações dos dias 19, 20 e 21 de julho de 2010 ficaram conhecidas como a segunda grande ação coletiva da Marcha. Isto desencadeou no desafio central do movimento ao reivindicar a paz com um bem de justiça social da nação.

Neste ínterim é importante ressaltar que a jornada política de emancipação da paz como um bem de interesse social contraria o interesse egoísta das oligarquias políticas e institucionais encasteladas no poder daquela nação. Isto, na prática, gerou um certo "desconforto" institucional, pois na primeira grande ação coletiva houve forte tensão nas instituições militares do governo.

Curiosamente, a multidão de ativistas provocou receio e tensão na caserna colombiana, uma vez que se temia que essa mobilização pudesse disseminar um conjunto de revolta popular de dimensões imprevisíveis. Sobre isso é revelador observar que: 
Durante os dias, 19, 20 e 21 de julho de 2010 chegaram os representantes e a maioria se reúnem na Universidade Nacional (UM). Foi nesta universidade que a multidão se aglomerou em cabildos. A universidade colapsou e não havia mais espaço onde hospedar o pessoal. Eu levei o pessoal na minha casa aqui em Bogotá e todos fizemos a mesma coisa. Bogotá encheu de camponeses, indígenas, afros. (EL PROFE, 2017).

A segunda ação coletiva da Marcha, como já foi dito acima, teve a ver com a formalização do movimento ocorrido nos dias 21, 22 de abril de 2012 após a concentração no Centro de Convenções de Bogotá. Naquela oportunidade perto de 80 mil pessoas de diferentes regiões do país acompanharam o evento. Havia mais de 1700 organizações fazendo parte do "Movimento Político e Social Marcha Patriótica pela Segunda e Definitiva Independência" (MARCHA PATRIÓTICA, 2012 a).

Para fechar este ciclo de emergência do movimento no dia 23 de abril o evento finalizou com uma mobilização pelo centro da cidade exibindo símbolos e declarando refrãos bolivarianos. Neste aspecto é precioso ressaltar que ocorreu algo seminal: a declaração política nacional do movimento que manifestou empenho na procura de uma solução política para o conflito armado.

Tal declaração foi resultado daquelas concentrações reivindicatórias apresentadas acima. Isto mobilizou enfaticamente a construção do processo de paz com o propósito de impulsionar processos constituintes regionais e locais em prol da solução política da paz com justiça social, as quais convergiriam na Assembleia Nacional Constituinte (MARCHA PATRIÓTICA, 2012b).

Neste contexto de reivindicar a paz como um bem de Justiça social emergiu a Greve Nacional pela Soberania, pela Terra e pelo Território contra 0 Modelo Econômico Dominante. Vale ainda registrar que no dia 12 de outubro os diversos movimentos sociais que advogam pela defesa da paz como um bem da nação instituíram a data como Dia da Dignidade.

Nesse momento representativo convocou-se a sociedade colombiana para um grande debate sobre a importância da paz como um bem comum para o país: o Grande Debate Nacional pela Paz e pela Solução Política e Pacífica. (MARCHA PATRIÓTICA, 2012c).

Para aprofundar o entendimento da questão é valioso salientar que a Colômbia "fragmentou" o processo de socialização democrática do país ao "permitir" que os bens sociais da nação, tais como educação, saúde, cidadania entre outros fossem fragilizados pelo fenômeno da violência que por muitas décadas vem promovendo a "ausência" ou permissividade do Estado em muitas regiões da nação. 
A consequência desta permissividade pode ser compreendida como um dos fundamentos para a emergência de um para-estado seja de extrema direita - o caso do Paramilitarismo - seja de esquerda caso das guerrilhas ou ainda há que se reconhecer 0 estado paralelo dos narcotraficantes o que na prática resultou na formação de uma força denominada os senhores de la guerra (DUNCAN, 2006).

Assim sendo, o que conseguiu concretizar a Marcha foi o fomento pela unidade nacional como um clamor generalizado que encorajou os ativistas pela paz como bem comum, ou seja, a obrigação social da paz "estimulando a arte [pedagógica] de viver juntos (com-viver)" (MARTINS, 2019, p. 168, acréscimo nosso).

Por isso, as reivindicações feitas pelas mobilizações sociais no período de 2011 até 2016 contribuíram para abrir um canal efetivo de negociação entre o governo Santos e a guerrilha das Forças Armadas Revolucionárias da Colômbia- Exército Popular (FARC-EP). Isto, em certa medida, demonstrou o protagonismo das ações coletivas, porém também permitiu aflorar na sociedade colombiana o compromisso solidário como fator político e moral das ações coletivas em prol da paz como um bem de justiça social.

\section{O Paro Nacional Agrário: Tecendo Solidariedade Moderna}

O Paro Nacional Agrário neste artigo foi compreendido por nós como um dos repertórios de confronto mais significativo da Marcha, uma vez que isto se constituiu numa ação de ruptura. Por conseguinte, a relevância dessa ação se deu, principalmente, pelas ações simbólico-solidárias da ruana, pelos desafios políticos e pelas incertezas que ação coletiva despertou na sociedade colombiana em geral.

Desta forma, estrategicamente, o termo solidariedade moderna é entendida aqui como:

Não apenas como relação à existência de um ethos comunitário, que envolve os participantes num mesmo compromisso moral na vida, na perspectiva de partilhar um 'bem comum' (Arendt, 2003). O termo solidariedade implica igualmente, a pratica afetiva de relacionar-se com o outro, o exercício efetivo de uma pratica pública dos direitos em espaços coletivos (MARTINS; PINHEIRO, 2009, p. 135).

De maneira simultânea, o recesso dos diálogos de paz em Habana (Cuba) "coincidiu" na Colômbia com a greve agrária nacional (Paro Nacional Agrário y Popular) no dia 19 de agosto de 2013. 
Uma das causas do movimento ocorreu devido à denúncia feita pelos movimentos sociais sobre o não cumprimento dos acordos do governo Santos para com os agricultores e produtores de café que fazem parte da Mesa Nacional de Unidad Agropecuaria.

Com a repercussão das articulações em defesa da causa agrária novos atores sociais foram agregados a o movimento pela dignidade dos produtores de arroz, café, cacau, rapadura e batata.

Em linhas gerais, as manifestações sociais rejeitam os acordos do livre comércio e reivindicam subsídios das suas produções por parte do governo, assim como o corte dos impostos de matérias-primas e dos insumos agrícolas importados.

O precedente das organizações que fizeram parte das negociações no norte de Santander (13/06/2013) e da greve mineira (19/07/2013) observamos que a Mesa Nacional Agropecuaria y Popular de Interlocución y Acuerdo (MIA) foi outro coletivo que aderiu ao movimento.

Para estas organizações do movimento popular o acesso à terra e a luta pela reforma agrária são basilares para a conquista de direitos coletivos dos camponeses. Sobretudo, pelo fato destas reivindicações possibilitarem abertura de negociação política com os trabalhadores da mineração extrativista e a conquista de investimentos sociais como a garantia dos direitos para quem trabalha na extração de minerais. Estas pautas fizeram parte das razões que mobilizaram o paro nacional.

Ao aprofundar a discussão identificamos que nesta greve nacional também participou o Coordinador Nacional Agrario (CNA) que agrupa trinta organizações de dez estados da nação. Este ator social reivindicou os direitos de exploração do extrativismo mineral de grande porte, a proteção da mineração artesanal de pequena escala, luta pela conquista de direito trabalhista e pela defesa de políticas de assistência social.

Neste interesse de compreender as especificidades desta mobilização social percebemos que a Marcha teve que enfrentar ação política discriminatória sobre o ativismo social em defesa da paz com justiça social. Tal fato pode ser caracterizado com a descaracterização da luta pela paz feita pelo governo Santos. O trecho seguinte é esclarecedor ao revelar que: "a tal (sic) greve nacional agrária não existe" (PRESIDENCIA DE LA REPUBLICACOLOMBIA, 2013).

Paradoxalmente, Isso promoveu maior indignação nacional e descontentamento com a presidência nacional que não reconhecia a relevância daquelas reivindicações sociais.

Curiosamente, pouco tempo depois, reconhecendo a gravidade da situação político-social que vivenciava o país os meios de comunicação 
começaram a alertar para a serenidade das mobilizações sociais e das consequências de negligenciar isto.

"Espontaneamente", em poucas horas emergiu uma série de protestos o que obrigou a presidência da república reconsiderar a afirmação de menosprezo para com as pautas mobilizadas pela Marcha e os outros coletivos sociais (EL ESPECTADOR, 2013a). Mesmo com a postura de retratação presidencial desencadeou-se uma série de protestos conhecidos como panelaços. Todo este processo de reivindicação social fez com que um novo símbolo de resistência emergisse, a saber: a Ruana.

Este novo frame foi responsável pelo maior desempenho das ações coletivas naquele momento, visto que houve maior sentimento de indignação, ampliação da unidade popular e uma aliança de interesses solidários (ou uma espécie de desinteressamento maussiano) das causas sociais envolvendo as dimensões urbana e rural da sociedade colombiana.

Em termos das práticas sociais mobilizadas pelo espírito do dom, ou seja, pela obrigação de reciprocidade mútua e livre entre os atores pudemos observar que o sentimento de indignação coletiva generalizada não ocorreu de forma oportunista e inconsequente como geralmente ocorre em manifestações políticas motivada por intolerância ideológica, por exemplo.

Ao contrário disso, observamos a constituição de atitudes políticas voltadas para a noção de cidadania ativa como observou Martins (2012) que inclui uma dimensão de gratuidade para se realizar como direito coletivo. Isto implicou compreender que a cidadania não é apenas uma ideia abstrata, mas sim a conquista de direitos, a ressignificação de modos de viver em comunidades de paz o que pode diminuir a precariedade político-social da relação sociedade-estado colombiano.

Assim sendo identificamos que essas ações coletivas permitiram práticas de solidariedade moderna compatíveis com 0 pensamento neomaussiano, ou melhor, como o "dom nobre".

Diante disto foi possível compreender as manifestações espontâneas conhecidas como cacerolazos ou panelazos ocorridas nos dias 25 e 26 de agosto 2013 com um exemplo típico de dom nobre, uma vez que essa mobilização popular emergiu generosamente com o intuito de repensar novas formas de viver e lutar por bens de interesse social do grupo.

Sobre a constituição de ações coletivas mobilizadas pelo espírito do dom é interessante perceber também que no mesmo dia do discurso presidencial que desconsiderava as ações coletivas do paro agrário nacional os habitantes

\footnotetext{
${ }^{8} \mathrm{O}$ dom nobre conceito/noção que Marcel Mauss defendeu mediante a retomada da generosidade e do "desinteressamento". Este último diz respeito ao neologismo no pensamento neomaussiano de Alain Caillé que faz do dom uma certa espontaneidade desinteressada mais que também continua vinculado ao interesse seja este um interesse instrumental (interesse em) ou interesse pelo outro (interesse por). (CAILLÉ, 2013).
} 
de Tunja 9 saíram às ruas para gritar contra o governo que "a Tal Greve" sim existia e que cessasse a repressão contra o protesto social. No dia seguinte o barulhento protesto estava sendo replicado ao menos 13 cidades colombianas, entre elas as mais populosas como Bogotá, Cali e Medellín. (EL ESPECTADOR, 2013b).

Por conseguinte, tal repertório de ação permitiu evidenciar a espontaneidade do agir coletivo na medida em que o lema "\#yomepongolaruana" em tradução livre (\#eubotominharuana) ${ }^{10}$ conseguiu convocar várias cidades que aparentemente nada tinham a ver com as reivindicações da greve camponesa, porém nessas ações coletivas foi possível verificar o interesse pelo outro, sobretudo, no lema "todos somos agro descendientes". Estes elementos de reconhecimento social das ações coletivas ampliaram canais de solidariedade na dimensão transnacional do protesto colombiano.

Destarte, estas ações sociais repercutiram em países como Espanha, Alemanha, México e Argentina, dentre outros. O eco da transnacionalidade dos movimentos sociais exigia soluções para a crise agrária e respeito para com os manifestantes da ruana. Um dos líderes sociais da greve ligado à associação dos produtores de cebola descreveu o acontecimento assim:

Sempre falo que o maior ganho da greve foi criar consciência. A união dos camponeses com as grandes cidades foi um ato sem precedentes. O que era com os campesinos era com todos. O povo estava cansado e a greve foi um acordar, foi demonstrar que ao colombiano interessa-lhe sim o seu país, interessa-Ihe sim saber quem o governa. Sim! E possível unirse e mobilizar-se em prol de um objetivo comum (El espectador, 2013c, tradução nossa).

Dez dias após do início da greve Bogotá foi paralisada por mobilizações de diferentes setores como sindicais, camponeses e estudantes expressando solidariedade com os camponeses e, ao mesmo tempo, reivindicando suas demandas próprias.

Por conseguinte, esta força simbólico-solidária da ruana disseminou-se em diferentes mobilizações da Colômbia, pois em outro evento ligado á greve nacional, a batucada nacional pela educação como repertório da Mesa Amplia

\footnotetext{
${ }^{9}$ É interessante esclarecer que Tunja é a capital de um dos estados agrícolas mais representativos da Colômbia. O uso da ruana é cotidiano, pois a cidade está postada no topo dos andes colombianos. É desta região andina a ideia de vestir a ruana como símbolo de solidariedade às lutas dos camponeses que estavam sendo implementadas em diferentes regiões do país. Este evento ficou conhecido como "a rebelião da ruana".

${ }^{10}$ É fundamental entender neste contexto que o ato de pôr a ruana explicita uma atitude solidária de reconhecimento identitários das raízes camponesas que foi replicado em todo o país.
} 
Nacional Estudantil (MANE), que também integra Marcha Patriótica, utilizou a metáfora anti-utilitarista da ruana, uma vez que nesta ação coletiva o lema "Todos com ruanas e com atabaques em solidariedade com a greve agrária também" mobilizou o protesto (EL ESPECTADOR, 2013c, tradução nossa).

Em síntese, a rebelião da ruana mostrou uma solidariedade social entre coletivos sociais com mobilização nacional jamais conhecida na história recente da Colômbia. Em parte, tal mobilização ocorreu como uma resposta às críticas do presidente Santos, porém identificou-se também a pratica moral de justiça para com as demandas dos camponeses e que o próprio Santos aceitou as reivindicações como reais e válidas.

Com efeito, a obrigação de apoiar ou proteger os interesses dos camponeses para preservar e proteger os próprios interesses tiveram significativo reconhecimento social. Por isso, vale ressaltar que durante as diversas manifestações que compuseram o paro nacional agrário ocorria, paralelamente, os tratados de paz em Habana (Cuba) discutindo justamente as questões de reforma agrária inerente aos acordos de paz. Isso demonstrou como a questão agrária constitui uma variável de interesse comum fundamental nas ações coletivas que defendem a paz com justiça social.

\section{Considerações finais}

Entender que nas ações coletivas coabitam além do interesse ou propósito comum a obrigação social para com o outro e a generosidade para com o grupo consistiu entender que a solidariedade moderna junta de forma paradoxal 0 interesse e a espontaneidade presente na prática social da Marcha. Logo, o prazer, a satisfação e a obrigação de lutar pela paz com justiça social deixou de ser apenas um ativismo de um grupo político e constitui-se num bem de interesse antiutilitarista da nação.

A metáfora de desinteressamento da ruana levar-nos a compreender como a dimensão simbólica da solidariedade promove sentido humanista e solidário ao agir dos indivíduos. Por seu turno, percebemo-la não apenas como um elemento de identidade camponesa ela metamorfoseou-se num propósito político de coletividade, de resistência, de indignação e de alianças moralmente motivados, ou seja, transformou-se numa experiência de comum existência anti-utilitairsta da sociedade colombiana.

É neste sentido paradoxal de espontaneidade e obrigação que as ações coletivas moralmente motivadas são desenvolvidas. Paz com justiça social sugere reconhecimento do outro, pelo comprometimento com o coletivo e pelo sentimento de dívida para com outro. Assim, falar de paz com justiça social também implica melhores condições para a grande comunidade colombiana. 
Ações coletivas e suas configurações antiutilitaristas:

O caso colombiano da Marcha Patriótica

Aprofundando nossa interpretação ousamos ao afirmar que na práxis do mundo pedagógico-político-social a metáfora da ruana demonstrou como a generosidade e o interesse coabitam no agir solidário das ações coletivas para além de um interesse racional-egoísta que desmonta a ideia de democracia contemporânea latino-americana.

\section{REFERÊNCIAS}

BRINGEL, Breno; PLEYERS Geoffrey. Protesta e indignación global: los movimentos sociales em el nuevo orden mundial. Bs As: CLACSO/ RJ: FAPERJ, 2017.

CAILLÉ, Alain. Antropologia do dom: o terceiro paradigma. Petrópolis: Editora Vozes, 2002.

CAILLÉ, Alain. O Dom entre interesse e "desinteressamento". Revista de Estudos Antiutilitaristas e Pós-Coloniais. v. 3, n. 1, p. 7-42, 2013.

DUNCAN, Gustavo. Los Señores de la Guerra. Bogotá: Editorial Planeta, 2006.

EI ESPECTADOR. Presidente admitió que la embarró al decir "el tal paro agrario no existe". El Espectador, Bogotá, 20 de septembro de 2013ㄹ. Disponível em:

$<$ https://www.elespectador.com/noticias/politica/presidente-admitio-embarro-al-decir-eltal-paro-agrario-articulo-447581 >. Acesso em: 10 de out. de 2018.

EI ESPECTADOR. Paro agrario: cacerolazo también retumbó en Bogotá. EI Espectador, Bogotá, 26 de agosto de 2013b. Disponível em: $<$ https://www.elespectador.com/noticias/nacional/paro-agrario-cacerolazo-tambienretumbo-bogota-articulo-442659 >. Acesso em: 10 de outubro de 2018.

EI ESPECTADOR. El paro como futuro. El Espectador, Bogotá,1 de septembro de 2013d. Disponível em: <https://www.elespectador.com/noticias/nacional/el-paro-futuroarticulo-443631>. Acesso em: 10 de outubro de 2018.

GODBOUT, Jacques; CAILLÉ, Alain. O Espírito da dádiva. Rio de Janeiro, Fundação Getulio Vargas, 1999.

GOHN, Maria da Gloria. Manifestações e protestos no Brasil: Correntes e contracorrentes na autalidade. São Paulo: Cortez, 2017.

LOZANO GUILLÉN, 2014. El nuevo país está en marcha. 1 ed. Bogotá: Ocean Sur, 2014.

MARCHA PATRIÓTICA. Carácter, Plataforma, Estructura y Declaración. Cartilha de divulgação da Marcha. Material em Físico (S/D).

MARCHA PATRIÓTICA. Marcha Patriótica a Bogotá. 3 de julho de 2010. Disponível em: <https://marchapatriotica.blogspot.com/ >. Acesso em: 11 de julho de 2018.

MARCHA PATRIÓTICA. Carta Abierta al Pueblo Colombiano. Prensa Rural, 7 de maio de 2012a. Disponível em: <http://www.prensarural.org/spip/spip.php?article8113 >. Acesso em: 10 de agosto de 2016. 
MARCHA PATRIÓTICA. Declaración política de la Marcha Patriótica. Prensa Rural, 24 de abril de 2012b. Disponível em:

$<$ http://www.prensarural.org/spip/spip.php?article8021 > Acesso em: agosto $10 \mathrm{de}$ 2016.

MARCHA PATRIÓTICA. Declaración Política del Comité Patriótico Nacional. Remap, 2 de junio de 2012c. Disponível em: <https://www.laremap.com/2012/06/declaracionpolitica-del-comite.html > Acesso em:23 de março de 2017

MARTINS, Paulo Henrique. A sociologia de Marcel Mauss: Dádiva, simbolismo e associação. Revista Crítica de Ciências Sociais, 73, Dezembro, 2005. p 45-66.

MARTINS, Paulo Henrique; PINHEIRO, R. Avaliação em Saúde na Perspectiva do Usuário: abordagem multicêntrica. Rio de Janeiro: CEPESC/IMS-UERJ; Recife: Editora da UFPE; São Paulo: Editora ABRASCO, 2009.

MARTINS, Paulo Henrique; PINHEIRO, R. La decolonidad de América Latina y la heterotopía de uma comunidade de destino solidaria. Buenos Aires: Editora CICCUS, 2012.

MARTINS, Paulo Henrique, ARAÚJO Marcos Silva. Democracia, pósdesenvolvimento e gestão de bens comuns perspectivas da América Latina e do Caribe. S.P: Annablume Editora, 2016.

MARTINS, Paulo Henrique, ARAÚJO Marcos Silva. Pensando heterotopías no contexto pós-colonial: convivialismo, amor e bem comum. CyCL Controversias y Concurrencias Latinoamericanas. Vol 10; No 18, abril - septembro, 2019. p. 159171.

PRESIDENCIA DE LA REPUBLICA- COLOMBIA, Presidente Juan Manuel Santos en la XXXV Caminata por la Solidaridad. 25 de agosto de 2013. Disponível em: $<$ https://www.youtube.com/watch?v=HWlj pj9IPU $>$. Acesso em: 26 de setembro de 2018.

\section{Entrevistas da Pesquisa:}

AMAUTA, 3 de fevereiro de 2017.

EL PROFE, 31 de janeiro de 2017. 